\title{
Prevalence of Asymptomatic Middle Cranial Fossa Floor Pits and Encephaloceles on MR Imaging
}

\author{
(D).C. Benson, (D). Lane, (D).R. Geske, (D).V. Gompel, and (D).N. Krecke
}

\begin{abstract}
BACKGROUND AND PURPOSE: Temporal lobe encephaloceles are increasingly identified and treated as epileptogenic foci. However, there is relatively scant research on the prevalence of asymptomatic encephaloceles. This study set out to describe the frequency of incidental temporal lobe encephaloceles and middle cranial fossa pits.

MATERIALS AND METHODS: A retrospective review was completed of high-resolution ( $\leq 0.5$-mm section thickness) axial T2WI for internal auditory canal protocol imaging. The presence and laterality of middle cranial fossa pits (small bony defects containing CSF) and encephaloceles (brain parenchyma protrusion through osseous defects with or without bony remodeling) were recorded. Electronic medical records of patients with encephaloceles were searched for a history of seizure.

RESULTS: A total of 203 patients were included in the final cohort; 106 (52.2\%) women. Forty-five (22.2\%) patients had middle cranial fossa pits: 14 (31.1\%) unilateral on the right, 17 (37.8\%) unilateral on the left, and 14 (31.1\%) bilateral. Ten (5.0\%) patients had $\geq 1$ encephalocele, none of whom had a documented history of seizure in the electronic medical record. No significant difference was noted in the frequency of pits or encephaloceles based on sex $(P=.332$ and $P=.383$, respectively) or age $(P=.497$ and $P=.914$, respectively).
\end{abstract}

CONCLUSIONS: Incidental middle cranial fossa pits are common findings, and their prevalence is not related to age or sex. Temporal lobe encephaloceles, though rarer, also exist occasionally among asymptomatic patients. Such findings have diagnostic implications for encephaloceles identified during imaging work-up for epilepsy.

ABBREVIATIONS: BHAG = brain herniation into arachnoid granulations; $M C F=$ middle cranial fossa

B oth middle cranial fossa (MCF) pits and temporal lobe encephaloceles are subtypes of cephaloceles, intracranial content herniations through calvarial defects. ${ }^{1} \mathrm{MCF}$ pits, focal bony dehiscences containing CSF but not brain parenchyma, likely represent arachnoid granulations protruding into the overlying bone; these may also be called "small meningoceles." ${ }^{2}$ Temporal lobe encephaloceles, comparatively, are protrusions of brain through focal defects in the bone. ${ }^{3,4}$ The etiologies of pits and encephaloceles are unknown, though some have posited that increased CSF pressure or volume could play a role. ${ }^{2,5}$

Temporal lobe encephaloceles are associated with a number of processes, including otorrhea, hearing loss, and recurrent

Received June 20, 2019; accepted after revision September 27.

From the Department of Neuroradiology (J.C.B., J.L., K.N.K.), Division of Biomedical Statistics and Informatics (J.R.G.), and Department of Neurosurgery (J.V.G.), Mayo Clinic, Rochester, Minnesota.

Please address correspondence to John C. Benson, 200 1st St. SW, Rochester, MN 55905; e-mail: benson.john3@mayo.edu

http://dx.doi.org/10.3174/ajnr.A6311 meningitis. ${ }^{6,7}$ Encephaloceles are also a known rare cause of epilepsy. ${ }^{3,48-10}$ The first reported case led to complete seizure freedom following temporal lobectomy for a patient with an MCF encephalocele. ${ }^{11}$ Since then, several other authors have reported seizure freedom following partial temporal lobectomy or lesionectomy for symptomatic lesions. ${ }^{12-15}$ Nevertheless, surgical resection of encephaloceles for refractory epilepsy remains nuanced because it remains uncertain whether encephaloceles can be routinely considered epileptogenic. ${ }^{16}$

The location and small size of such abnormalities have led to under-recognition on MR imaging. ${ }^{4}$ However, as spatial resolution of MRI continues to advance, particularly with the emergence of high-field imaging systems, the identification of MCF pits and encephaloceles can be expected to increase with time. ${ }^{17,18}$ The clinical import and prevalence of pits and encephaloceles, therefore, deserve further investigation because both findings may be a source of diagnostic confusion and consternation. This study aimed to assess the prevalence of MCF encephaloceles and pits on high-resolution MR imaging in asymptomatic patients. 


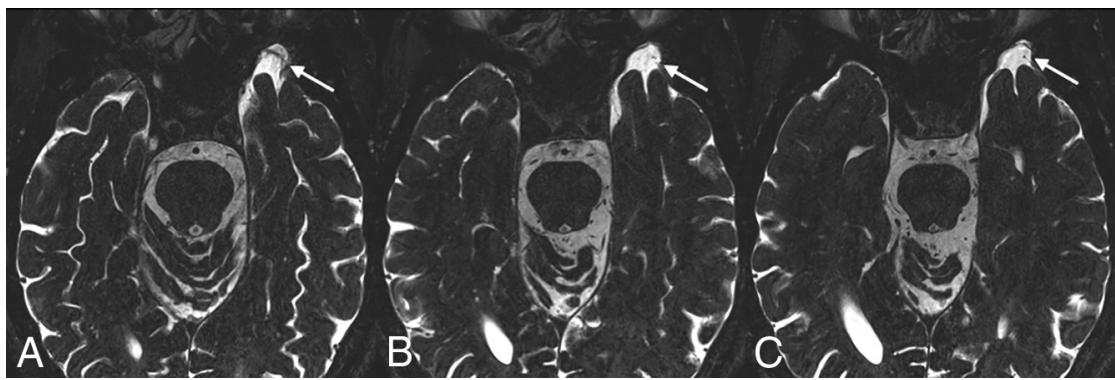

FIG 1. A 53-year-old man who presented with intermittent episodes of imbalance and leftgreater-than-right sensorineural hearing loss. Axial T2 SPACE images (from inferior to superior, AC) demonstrate a focal osseous defect in the greater wing of the left sphenoid bone containing CSF, consistent with an MCF pit (arrow). No herniation of brain parenchyma is present.
When a potential encephalocele was identified, the source thin axial T2 images were inspected in multiplanar reformatted images generated on a diagnostic radiology workstation running Visage Software, Version 7.1.12 (Visage Imaging, San Diego, California). Encephalocele was confirmed if the temporal lobe cortex extended into the inner table defect. Location of the encephalocele was assigned following the classification described by Wilkins, et al. ${ }^{19}$

\section{Statistical Analysis}

Association of the presence or absence

Table 1: Number and frequency of MCF pits and encephaloceles based on laterality ${ }^{a}$

\begin{tabular}{lccc}
\hline & Right & Left & Bilateral \\
\hline MCF pits (No.) (\%) & $14(31.1 \%)$ & $17(37.8 \%)$ & $14(31.1 \%)$ \\
Encephaloceles (No.) (\%) & $4(40 \%)$ & $5(50 \%)$ & $1(10 \%)$ \\
\hline
\end{tabular}

${ }^{\text {a }}$ Percentages are of the number of patients in which either pits or encephaloceles were observed.

\section{MATERIALS AND METHODS}

\section{Patient Selection}

Institutional review board approval was obtained for this study. A retrospective review was completed of all internal auditory canal MR imaging examinations performed between January 1, 2017, and June 30, 2018. Included patients had the following: 1) MR imaging examination including a $0.5-\mathrm{mm}$ axial T2 sampling perfection with application-optimized contrasts by using different flip angle evolutions (SPACE; Siemens, Erlangen, Germany) sequence or CISS or FIESTA images, and 2) imaging FOV that encompassed the osseous walls of the MCF bilaterally, requiring craniad coverage from the floor of the fossa to the floor of the sella or higher. Axial sequences were part of the dedicated internal auditory canal protocol used in our institution. Patients were excluded if images were of suboptimal quality (eg, degraded by motion artifacts).

\section{Imaging and Clinical Review}

Two neuroradiologists and a neuroradiology fellow reviewed MR images for the presence or absence of MCF "pits" (defined as extension of meninges and CSF through the inner table of the skull base, but not through the outer table, with or without bony remodeling) and the presence or absence of MCF "encephaloceles" (defined as extension of brain parenchyma through the aforementioned defect). Similar defects of the anterior and posterior cranial fossae were excluded from analysis. Lateralization (right versus left) was noted for encephaloceles and pits. For patients in whom $\geq 1$ encephalocele was detected, a review of the electronic medical record was completed to assess a history of seizures. The body mass index of each patient was also assessed because elevated body mass indices are known to be associated with idiopathic intracranial hypertension; these were found via a retrospective review of the electronic medical record. of MCF pits or encephaloceles with sex was examined using a $\chi^{2}$ test. Differences in age by the presence or absence of MCF pits or encephaloceles was examined using $t$ tests. Analyses were conducted using SAS (Version 9.4; SAS Institute, Cary, North Carolina).

\section{RESULTS}

Of the 204 patients who met the inclusion criteria for this study, one was excluded due to incomplete visualization of the MCF. Hence, 203 patients composed the patient cohort; 106 (52.2\%) were women. The mean patient age was $53.4 \pm 10.0$ years.

Forty-five of 203 (22.2\%) patients had MCF pits (Fig 1). Of the pits detected, $17 / 45$ (37.8\%) were unilateral on the left, $14 / 45$ (31.1\%) were unilateral on the right, and $14 / 45$ (29.2\%) were bilateral (Table 1).

Ten of 203 patients (5\%) had 15 encephaloceles (Figs. 2 and $3)$. Nine of the 10 patients had single encephaloceles, 5 on the left. One patient had 6 encephaloceles, 3 on each side. Twelve encephaloceles were located in the greater wing of the sphenoid bone; the other 3 , in the temporal bone. The greater sphenoid wing encephaloceles were most numerous in the anterior-inferior dural surface (10 of 12,83\%), with the remaining 2 located posteriorly, immediately lateral to the foramen spinosum and deep to the sphenoid spine. In the temporal bone, 2 of the 3 encephaloceles were located in the temporal squamosa immediately lateral to the sphenosquamosal suture; the third was located in the tegmen. Six of the 15 encephaloceles (40\%) demonstrated gliosis or volume loss, compatible with encephalomalacia. The size of the observed encephaloceles ranged from 3 to $10 \mathrm{~mm}$ (mean, $6 \mathrm{~mm}$ ). Six of $15(40.0 \%)$ had some degree of associated encephalomalacia of the adjacent parenchyma. None of the patients with encephalocele had a history of seizures or epilepsy. None of the patients with encephaloceles had a known or suspected history of elevated intracranial pressure.

The prevalence of MCF pits in women was $26.4 \%$, compared with $20.6 \%$ in men; no significant difference was noted in the prevalence of pits along sex lines $(P=.332)$. Similarly, no significant difference was observed between the frequency of encephaloceles and sex (5.7\% for women versus 3.1\% for men, $P=.383$ ). Additionally, there was neither a significant difference in the mean age of patients with MCF pits $(54.3 \pm 8.7$ 


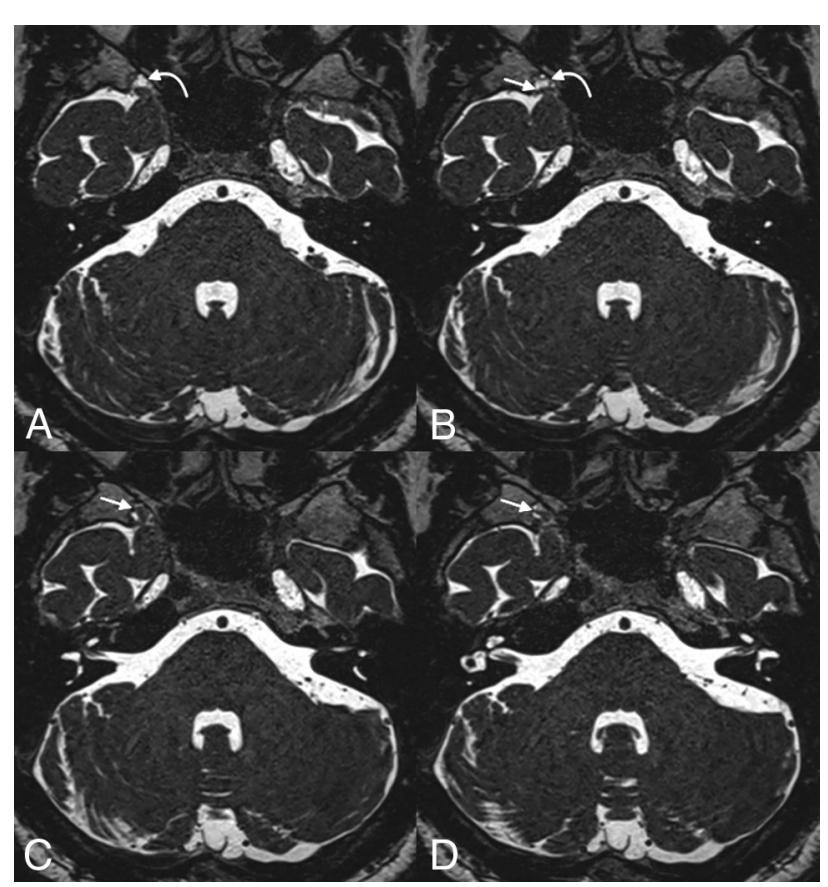

FIG 2. A 65-year-old man with a history of progressive bilateral sensorineural hearing loss. From superior to inferior $(A-D)$, axial T2 SPACE images demonstrate a focal dehiscence of the medial right greater wing of the sphenoid (curved arrows in $A$ and $B$ ). A small right temporal lobe encephalocele is seen protruding into the bony defect (straight arrows in $B-D$ ).

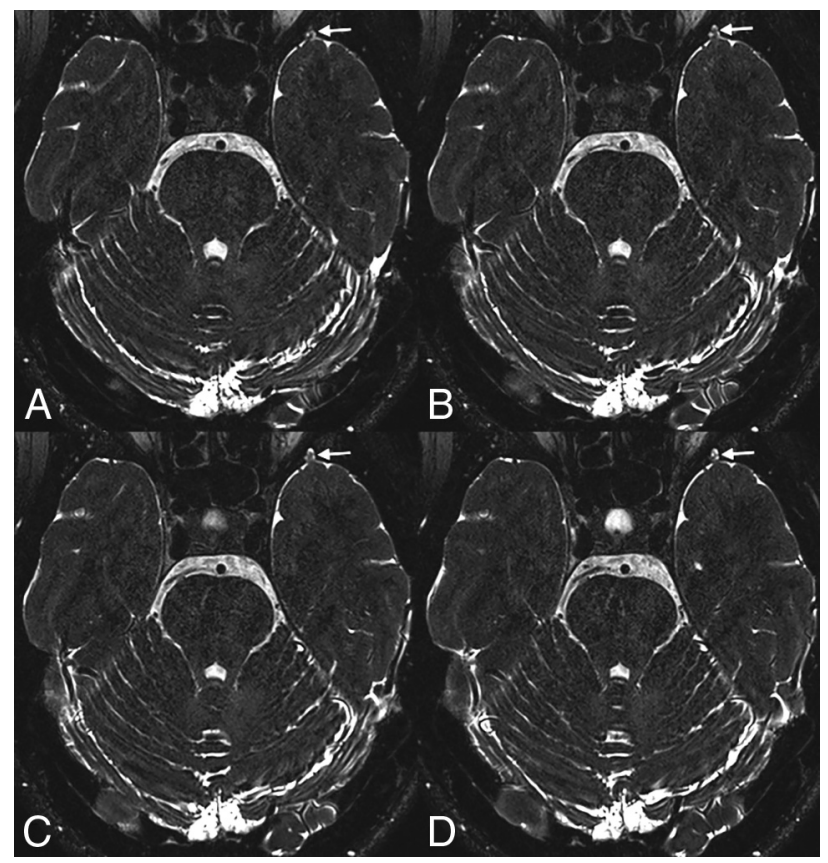

FIG 3. A 47-year-old woman who presented with a 2-month history of vertigo. From inferior to superior $(A-D)$, images demonstrate a small incidental encephalocele protruding into the greater wing of the left sphenoid (arrows).

years) compared with those without (53.2 \pm 10.4 years, $P=.497)$ nor a significant difference between the mean age of patients with encephaloceles (53.1 \pm 10.1 years) compared with those without $(53.5 \pm 10.1$ years, $P=.914)$ (Table 2).
Table 2: Comparisons of MCF pit and encephalocele frequency with age

\begin{tabular}{lccc}
\hline & Present & $\begin{array}{c}\text { Not } \\
\text { Present }\end{array}$ & $\begin{array}{c}\boldsymbol{P} \\
\text { Value }\end{array}$ \\
\hline MCF pits (mean age) (yr) & $54.3 \pm 8.7$ & $53.2 \pm 10.4$ & .497 \\
Encephaloceles (mean age) (yr) & $53.1 \pm 10.1$ & $53.5 \pm 10.1$ & .914 \\
\hline
\end{tabular}

No association was found between patient body mass index and the presence of dural pits $(P=.267)$, nor was an association found between body mass index and encephaloceles $(P=1.000)$.

\section{DISCUSSION}

Most MCF pits likely arise from aberrant arachnoid granulations. Such aberrantly located arachnoid granulations expand into the calvaria but do not communicate with a venous sinus. ${ }^{20}$ Protrusion of parenchyma through these defects, commonly called brain herniation into arachnoid granulations (BHAG), is a well-documented imaging finding, though it is more often described in the posterior fossa and along the larger sinuses. ${ }^{5,20-22}$ BHAG can be associated with abnormal signal of the herniated, or adjacent, parenchyma, though the findings rarely seem to be symptomatic. ${ }^{5}$ Some authors, such as Battal and Castillio, ${ }^{23}$ have sought to differentiate BHAG from classic temporal lobe encephaloceles. However, the distinction between the entities is somewhat opaque, raising the suspicion that encephaloceles and BHAG exist on a spectrum based on the severity of osseous thinning and/or remodeling. Thus, the current study will refer to brain herniation through any osseous defect as an encephalocele.

Spontaneous encephalocele is an extension of cerebral tissue and coverings into or through a defect in the skull not caused by trauma, inflammation, neoplasm, or surgical disruption. In our cohort, 14 of the encephaloceles involved the greater wing of the sphenoid bone or immediately adjacent temporal squamosal, lateral to the cranial base neural foramina (rotundum, ovale, and spinosum) and projected anteriorly or anterior-inferiorly through the inner table. A single encephalocele was located posteriorly and inferiorly in the tegmen tympani, lateral to the otic capsule and geniculate ganglion. Wilkins et $\mathrm{al}^{19}$ classified spontaneous temporal encephaloceles into 5 types, including anterior-inferior and posterior-inferior. The spontaneous anterior-inferior encephalocele is the type most commonly reported in the epilepsy literature associated with refractory temporal lobe epilepsy. ${ }^{24}$ The current study did not identify clinically occult encephaloceles of the other 3 types (anterior/spheno-orbital, anterior-medial/sphenoid sinus, or lateral/pterional). This absence may be an artifact of the volume of coverage, with the thin T2 images centered on the internal auditory canals typically not spanning the full height of the middle cranial fossa; however, in the authors' experience, these latter types are rare in asymptomatic patients.

The identification and treatment of temporal lobe encephaloceles for refractory temporal lobe epilepsy have increased in recent years. ${ }^{25}$ The incidence of asymptomatic encephaloceles noted in the current study underscores the potential diagnostic dilemma encountered when a temporal lobe encephalocele is discovered-that is, should a temporal lobe encephalocele, identified on otherwise normal MR imaging findings of a patient with refractory epilepsy, be targeted as the potential 
epileptogenic focus? Alternatively, should an encephalocele ipsilateral to mesial temporal sclerosis be considered dual pathology? Future research may be useful to identify characteristics of encephaloceles that carry a higher risk of seizure foci, such as size, morphology, and abnormal signal. Until such data are gathered, radiologists and epileptologists may continue to take into account the clinical context as well data points from other modalities, including electroencephalography, PET MR imaging, SPECT, and magnetoencephalography.

To our knowledge, there have been no reported cases in which MCF pits were implicated as the direct cause of seizures. Still, pits are of conceivable clinical import: They are likely precursors of encephaloceles and could represent an early form of a spectrum of pathology that includes all cephaloceles, both pits and encephaloceles. Nevertheless, the incidence of such pits is likely underestimated on imaging; a study by Chen et al found many more middle cranial fossa arachnoid granulations on cadaveric dissections than were seen on NCCT. ${ }^{26}$ Future studies may be useful to investigate how frequently pits progress to BHAG and encephaloceles.

Our study is limited by its retrospective nature. In addition, because the detection of MCF pits and encephaloceles was based solely on axial images, it is possible that smaller abnormalities may not have been detected. Thus, it is likely that the rate of small MCF abnormalities is underestimated in this study. A more comprehensive review using coronal and sagittal sequences may have superior sensitivity for the detection MCF abnormalities. Finally, although electronic medical records of patients with encephaloceles were reviewed for a history of seizure, it is unknown whether the observed pits and encephaloceles were truly asymptomatic.

\section{CONCLUSIONS}

MCF pits are frequently observed incidental and presumably asymptomatic findings on high-resolution T2-weighted MR imaging. Temporal lobe encephaloceles, some with evident encephalomalacia, are also occasionally seen among asymptomatic patients. The incidence of such findings should be taken into account when identifying or treating such lesions as possible epileptogenic foci.

\section{REFERENCES}

1. Settecase F, Harnsberger HR, Michel MA, et al. Spontaneous lateral sphenoid cephaloceles: anatomic factors contributing to pathogenesis and proposed classification. AJNR Am J Neuroradiol 2014; 35:784-89 CrossRef Medline

2. Lu CX, Du Y, Xu X-X, et al. Multiple occipital defects caused by arachnoid granulations: emphasis on T2 mapping. World J Radiol 2012;4:341-44 CrossRef Medline

3. Morone PJ, Sweeney AD, Carlson ML, et al. Temporal lobe encephaloceles. Otol Neurotol 2015;36:1439-42 CrossRef Medline

4. Abou-Hamden A, Lau M, Fabinyi G, et al. Small temporal pole encephaloceles: a treatable cause of "lesion negative" temporal lobe epilepsy. Epilepsia 2010;51:2199-202 CrossRef Medline

5. Liebo GB, Lane JJ, Van Gompel JJ, et al. Brain herniation into arachnoid granulations: clinical and neuroimaging features. $J$ Neuroimaging 2016;26:592-98 CrossRef Medline
6. Roehm PC, Tint D, Chan N, et al. Endoscope-assisted repair of CSF otorrhea and temporal lobe encephaloceles via keyhole craniotomy. J Neurosurg 2018;128:1880-84 CrossRef Medline

7. Van Gompel JJ, Miller JW. How epileptogenic are temporal encephaloceles?. Neurology 2015;85:1440-41 CrossRef Medline

8. Byrne RW, Smith AP, Roh D, et al. Occult middle fossa encephaloceles in patients with temporal lobe epilepsy. World Neurosurg 2010;73:541-46 CrossRef Medline

9. Urbach H, Jamneala G, Mader I, et al. Temporal lobe epilepsy due to meningoencephaloceles into the greater sphenoid wing: a consequence of idiopathic intracranial hypertension? Neuroradiology 2018;60:51-60 CrossRef Medline

10. Wang ZI, McBride A, Grinenko O, et al. Utility of CISS sequence in detecting anteroinferior temporal encephalocele. J Neurol Sci 2017;381:59-61 CrossRef Medline

11. Ruiz Garcia F. A case of temporal lobe epilepsy caused by an encephalocele [in Spanish]. Rev Esp Otoneurooftalmol Neurocir 1971;29:216-20 Medline

12. Bannout F, Harder S, Lee M, et al. Epilepsy surgery for skull-base temporal lobe encephaloceles: should we spare the hippocampus from resection? Brain Sci 2018;8 CrossRef Medline

13. Semenov MS, Belyakova-Bodina AI, Murtazina AF, et al. Surgery for intractable epilepsy in a patient with encephalocele of the temporal lobe: a case report [in Russian; Abstract available in Russian from the publisher]. Zh Vopr Neirokhir Im N N Burdenko 2017;81:99 CrossRef Medline

14. Toledano R, Jiménez-Huete A, Campo P, et al. Small temporal pole encephalocele: a hidden cause of "normal" MRI temporal lobe epilepsy. Epilepsia 2016;57:841-51 CrossRef Medline

15. Saavalainen T, Jutila L, Mervaala E, et al. Temporal anteroinferior encephalocele: an underrecognized etiology of temporal lobe epilepsy? Neurology 2015;85:1467-74 CrossRef Medline

16. Panov F, Li Y, Chang EF, et al. Epilepsy with temporal encephalocele: characteristics of electrocorticography and surgical outcome. Epilepsia 2016;57:e33-38 CrossRef Medline

17. Pittau F, Baud MO, Jorge J, et al. MP2RAGE and susceptibilityweighted imaging in lesional epilepsy at 7T. J Neuroimaging 2018;28:365-69 CrossRef Medline

18. De Ciantis A, Barba C, Tassi L, et al. 7T MRI in focal epilepsy with unrevealing conventional field strength imaging. Epilepsia 2016; 57:445-54 CrossRef Medline

19. Wilkins RH, Radtke RA, Burger PC. Spontaneous temporal encephalocele: case report. J Neurosurg 1993;89:492-98 CrossRef Medline

20. Rodrigues JR, Santos GR. Brain herniation into giant arachnoid granulation: an unusual case. Case Rep Radiol 2017;2017:8532074 CrossRef Medline

21. Malekzadehlashkariani S, Wanke I, Rüfenacht DA, et al. Brain herniations into arachnoid granulations: about 68 cases in 38 patients and review of the literature. Neuroradiology 2016;58:44357 CrossRef Medline

22. Sade R, Ogul H, Polat G, et al. Brain herniation into the transverse sinuses' arachnoid granulations in the pediatric population investigated with 3 T MRI. Acta Neurol Belg 2019;119:225-31 CrossRef Medline

23. Battal B, Castillo M. Brain herniations into the dural venous sinuses or calvarium: MRI of a recently recognized entity. Neuroradiol J 2014;27:55-62 CrossRef Medline

24. Wind JJ, Caputy AJ, Roberti F. Spontaneous encephaloceles of the temporal lobe. Neurosurg Focus 2008;25:E11 CrossRef Medline

25. Campbell ZM, Hyer JM, Lauzon S, et al. Detection and characteristics of temporal encephaloceles in patients with refractory epilepsy. AJNR Am J Neuroradiol 2018;39:1468-72 CrossRef Medline

26. Chen F, Deng Xf, Liu B, et al. Arachnoid granulations of middle cranial fossa: a population study between cadaveric dissection and in vivo computed tomography examination. Surg Radiol Anat 2011;33(3):215-21 